TITLE:

\title{
Charge traps in lead-halide perovskites with different grain sizes
}

$\operatorname{AUTHOR}(\mathrm{S})$ :

Kim, Do Hyung; Ohkita, Hideo

\section{CITATION:}

Kim, Do Hyung ... [et al]. Charge traps in lead-halide perovskites with different grain sizes. Japanese Journal of Applied Physics 2018, 57 : 08RE03.

\section{ISSUE DATE:}

2018-07-04

URL:

http://hdl.handle.net/2433/234846

\section{RIGHT:}

This is an author-created, un-copyedited version of an article accepted for publication in 'Japanese Journal of Applied Physics'. The publisher is not responsible for any errors or omissions in this version of the manuscript or any version derived from it. The Version of Record is available online at https://doi.org/10.7567/J JAP.57.08RE03; The full-text file will be made open to the public on 4 July 2019 in accordance with publisher's 'Terms and Conditions for Self-Archiving'.; の論文は出版社版でありません。引用の際には出版社版をご確認じ利用ください。; This is not the published version Please cite only the published version. 


\title{
Charge traps in lead-halide perovskites with different grain sizes
}

\author{
Hyung Do Kim ${ }^{1}$ and Hideo Ohkita ${ }^{1 *}$
}

${ }^{1}$ Department of Polymer Chemistry, Graduate School of Engineering, Kyoto University, Katsura, Kyoto 615-8510, Japan

*E-mail: ohkita@photo.polym.kyoto-u.ac.jp

It is crucially required to understand charge traps in $\mathrm{CH}_{3} \mathrm{NH}_{3} \mathrm{PbI}_{3}$ perovskites, which severely affect charge recombination mechanism and hence have a critical impact on photovoltaic performance. Herein, we studied the photoexcited dynamics of $\mathrm{CH}_{3} \mathrm{NH}_{3} \mathrm{PbI}_{3}$ perovskites with different grain sizes by measuring intensity dependence of time-resolved photoluminescence. As a result, we found that the photoluminescence (PL) decay for all the samples can be well analyzed by bimolecular radiative recombination and trap-assisted Shockely-Read-Hall recombination model. We discuss how the PL dynamics impact on the photovoltaic performance of $\mathrm{CH}_{3} \mathrm{NH}_{3} \mathrm{PbI}_{3}$ perovskite solar cells on the basis of the recombination analysis. 


\section{Introduction}

Solution processed organic-inorganic perovskites composed of $\mathrm{ABX}_{3}$ compositions, such as $\mathrm{CH}_{3} \mathrm{NH}_{3} \mathrm{PbI}_{3}$ and $\mathrm{CH}_{3} \mathrm{NH}_{3} \mathrm{PbI}_{3-x} \mathrm{Cl}_{x}$ have emerged as a promising material in application of photovoltaic devices because of their intriguing optoelectronic properties, including direct bandgap with excellent absorption coefficient, high charge carrier mobility, high long diffusion length, and Wannier-Mott exciton nature. ${ }^{1-7)}$ Consequently, organic-inorganic perovskite solar cells based on metal halides have been considered as a suitable candidate for alternative energy sources because they potentially provide flexible and light-weight devices with large-scale and low-cost production. ${ }^{5,8)}$ Owing to many research efforts, the power conversion efficiency (PCE) of perovskite solar cells has been rapidly improved in the past few years and recently exceeded $22 \%{ }^{8,9)}$

The photovoltaic performance of inorganic solar cells is generally dependent upon grain sizes of the active layer. ${ }^{10-12)}$ We have recently studied how grain sizes affect the photovoltaic performance of planar heterojunction $\mathrm{CH}_{3} \mathrm{NH}_{3} \mathrm{PbI}_{3}$ devices fabricated by the fast deposition-crystallization (FDC) procedure. ${ }^{13,14)}$ We found that all the photovoltaic parameters increase as the grain size of perovskites is increased. Consequently, the highest PCE of $19.4 \%$ was observed for the device with the largest grain size of $\approx 500 \mathrm{~nm}{ }^{13)}$ The enhancement in short-circuit current density $\left(J_{\mathrm{SC}}\right)$ is mainly ascribed to the increase in absorption efficiency of perovskites at longer wavelengths with increasing thickness of perovskite layers. As with the improvement in $J_{\mathrm{SC}}$, the open-circuit voltage $\left(V_{\mathrm{OC}}\right)$ is also increased with increasing grain size of perovskites. By analyzing the intensity dependence of $V_{\mathrm{OC}}$ on the basis of bimolecular radiative recombination and trap-assisted ShockleyRead-Hall (SRH) recombination, we found that the smaller $V_{\mathrm{OC}}$ observed for the perovskite device with the smaller grain size is due to the higher trap density $N_{\mathrm{t}}$. In other words, this finding suggests that the photovoltaic performance is limited by charge traps in $\mathrm{CH}_{3} \mathrm{NH}_{3} \mathrm{PbI}_{3}$ perovskites. Such charge traps have been reported to affect photoluminescence (PL) dynamics. ${ }^{15-19)}$

In this work, we study the $\mathrm{PL}$ dynamics in $\mathrm{CH}_{3} \mathrm{NH}_{3} \mathrm{PbI}_{3}$ perovskites with different grain sizes by measuring the intensity dependence of time-resolved PL (TRPL) spectroscopy. By analyzing the PL decay on the basis of the bimolecular radiative recombination and the trapassisted SRH recombination model, we have shown that trap density $\left(N_{\mathrm{t}}\right)$ is decreased with 
increasing grain size of perovskites. Such trend is in good agreement with our previous report analyzed from the intensity-dependent $V_{\mathrm{OC}}{ }^{13)}$ We further discuss the primary loss mechanism on the basis of quantitative analyses.

\section{Experimental methods}

\subsection{Materials and Sample Preparation}

A methylammonium iodide $\left(\mathrm{CH}_{3} \mathrm{NH}_{3} \mathrm{I}\right)$ was prepared by dropwise addition of a methanol solution of methylamine $\left(\mathrm{CH}_{3} \mathrm{NH}_{2}, 90 \mathrm{~mL}, 40 \%, 0.882 \mathrm{M}\right.$; Wako Pure Chemical Industries, Ltd.) over $10 \mathrm{~min}$ to an aqueous solution of hydrogen iodide (HI, $96.9 \mathrm{~mL}, 57 \mathrm{wt} \%, 1.29 \mathrm{M}$; Wako Pure Chemical Industries Ltd.) in a 500-mL round bottom flask at $0{ }^{\circ} \mathrm{C}$. The precipitates were recovered by evaporation at $50{ }^{\circ} \mathrm{C}$ for $30 \mathrm{~min}$ after stirring for $2 \mathrm{~h}$. The resultant yellowish raw products were dissolved in ethanol, recrystallized from diethyl ether, and then finally filtered. These steps were repeated three times. After the filtration, the white solid products $\mathrm{CH}_{3} \mathrm{NH}_{3} \mathrm{I}$ were dried at $60{ }^{\circ} \mathrm{C}$ in a vacuum oven for $24 \mathrm{~h}$. Perovskite stock solutions $\left(\mathrm{CH}_{3} \mathrm{NH}_{3} \mathrm{PbI}_{3}\right)$ were prepared by mixing $\mathrm{CH}_{3} \mathrm{NH}_{3} \mathrm{I}$ with purified $\mathrm{PbI}_{2}$ (Tokyo Chemical Industry with Co., Ltd., Japan) at a molar ratio of 1 to 1 in anhydrous $N, N$ dimethylformamide (DMF, 99.8\%, Sigma-Aldrich) with different concentration of $25 \mathrm{wt} \%$ (316 $\left.\mathrm{mg} \mathrm{mL}^{-1}\right), 45 \mathrm{wt} \%\left(778 \mathrm{mg} \mathrm{mL}^{-1}\right)$, and $55 \mathrm{wt} \%\left(1160 \mathrm{mg} \mathrm{mL}^{-1}\right)$ and then stirred at $70{ }^{\circ} \mathrm{C}$ overnight in a nitrogen-filled glove box $\left(\mathrm{H}_{2} \mathrm{O}\right.$ and $\left.\mathrm{O}_{2}<1 \mathrm{ppm}\right)$.

The glass substrates were washed with toluene, then acetone, and finally ethanol in an ultrasonic bath for $15 \mathrm{~min}$ each and then dried under nitrogen flow. The washed substrates were further treated with a UV-ozone cleaner (Nippon Laser \& Electronics Lab., NLUV253S) for $30 \mathrm{~min}$. Perovskite films were prepared atop the UV-ozone-cleaned substrate by spin-coating at $5000 \mathrm{rpm}$ for $30 \mathrm{~s}$, and after $6 \mathrm{~s}$, anhydrous chlorobenzene (99.8\%, 0.3 mL, Sigma-Aldrich) was quickly dropped onto the center of the substrate. The instant color change of films from yellow to brown was observed upon dropping chlorobenzene solvent. The resulting dark brown films were dried at $100{ }^{\circ} \mathrm{C}$ for $10 \mathrm{~min}$. The grain size of resultant films was simply controlled by the different concentration of perovskite stock solution.

\subsection{Measurements}


The surface morphology and thickness of perovskite films were measured with an atomic force microscope (AFM) (Shimadzu, SPM-9600) with a silicon probe in contact mode and a scanning electron microscope (SEM) (Keyence, VE-9800). Time-resolved photoluminescence (TRPL) were measured by a time-correlated single photon-counting (TCSPC) fluorescence lifetime system (Horiba Jobin Yvon, FluoroCube). The samples were excited by a pulse laser with a photon energy of $1.84 \mathrm{eV}$ and a pulse width of $<1 \mathrm{~ns}$. The excitation intensity was reduced to $\sim \mathrm{nJ} \mathrm{cm}{ }^{-2}$ by using the neutral density (ND) filters to avoid electron-hole annihilation processes. A pulse picker was used to reduce the pulse repetition rate to $1 \mathrm{MHz}$, allowing measurements of lifetimes in the hundreds of nanosecond range. The samples were excited at $1.84 \mathrm{eV}$ and the emission was collected at $1.60 \mathrm{eV}$ after passing a long-pass filter to prevent an incoming excitation laser reflected. The external quantum efficiency (EQE) spectra were measured with a spectral response measurement system (Bunkoukeiki, ECT-250D). The power of the incident monochromatic light was kept under $0.05 \mathrm{~mW} \mathrm{~cm}^{-2}$, which was measured with a calibrated silicon reference cell (Bunkoukeiki, BS-520BK).

\section{Results and discussion}

\subsection{Film Morphology}

Figure 1 shows the SEM and AFM images of $\mathrm{CH}_{3} \mathrm{NH}_{3} \mathrm{PbI}_{3}$ films prepared by the FDC method. As shown in the figure, $\mathrm{CH}_{3} \mathrm{NH}_{3} \mathrm{PbI}_{3}$ perovskite layers are flat and pin-hole free, which are homogeneously covered with relatively uniform grain sizes. In addition, the grain size of perovskites increased as the concentration of perovskite stock solution increased. On the other hand, the higher concentration of stock solution was employed, the wider distribution of grain size was observed. The average grain size of $\mathrm{CH}_{3} \mathrm{NH}_{3} \mathrm{PbI}_{3}$ perovskite was estimated to be $\approx 100 \mathrm{~nm}$ for the $25 \mathrm{wt} \%$ stock solution, $\approx 300 \mathrm{~nm}$ for the 45 $\mathrm{wt} \%$ stock solution, and $\approx 500 \mathrm{~nm}$ for the $55 \mathrm{wt} \%$ stock solution. More interestingly, as shown in Figure 1d, the average grain size is almost the same as the thickness of $\mathrm{CH}_{3} \mathrm{NH}_{3} \mathrm{PbI}_{3}$ layers: $\approx 100 \mathrm{~nm}$ for the $25 \mathrm{wt} \%$ stock solution, $\approx 300 \mathrm{~nm}$ for the $45 \mathrm{wt} \%$ stock solution, and $\approx 500 \mathrm{~nm}$ for the $55 \mathrm{wt} \%$ stock solution. This suggests that $\mathrm{CH}_{3} \mathrm{NH}_{3} \mathrm{PbI}_{3}$ perovskite layers prepared by the FDC method are composed of monograins in the direction normal to the substrate. These results are in good agreement with our previous report. ${ }^{13)}$ 


\subsection{Absorption and PL Spectra}

Figure $2 \mathrm{a}$ shows the absorption and steady state $\mathrm{PL}$ spectra of the $\mathrm{CH}_{3} \mathrm{NH}_{3} \mathrm{PbI}_{3}$ perovskite film with a grain size of $\approx 500 \mathrm{~nm}$. As shown in the figure, the onset of absorption spectra is equal to the maximum peak position of the PL spectra, which is indicative of the direct bandgap semiconductors. ${ }^{1,2)}$ As shown in Figure $2 b$, a direct bandgap was evaluated from the $x$-axis intercept of $(E \times \mathrm{EQE})^{2}$ plotted against the photon energy $E .^{20-23)}$ The bandgap energy increased from 1.57 to $1.59 \mathrm{eV}$ with decreasing grain size of perovskites. These results are consistent with previous reports. ${ }^{23-26)}$

\subsection{PL Dynamics}

Figure 3 shows the intensity dependence of the TRPL dynamics of $\mathrm{CH}_{3} \mathrm{NH}_{3} \mathrm{PbI}_{3}$ perovskite films with different grain sizes at room temperature. As shown in the figure, no singleexponential decay was observed for all the samples, suggesting that there are several emissive species with different lifetime. However, this is not the case because no spectral change was observed for the TRPL over the time range measured, as shown in Figure 4. This indicates that the radiative PL decay is attributed to one emissive species. In $\mathrm{CH}_{3} \mathrm{NH}_{3} \mathrm{PbI}_{3}$ perovskites, photoexcited states can be easily dissociated into free electrons and holes because the exciton binding energy is less than the thermal energy at room temperature. ${ }^{4-7)}$ Thus, such radiative PL is ascribed to the bimolecular recombination of free electrons and holes as will be discussed below.

\subsection{PL Decay Analyses}

We here analyze the PL decay dynamics in more details to address the origin of the nonexponential kinetics. The PL decays were well fitted by a double-exponential decay function. As shown in Figure 5, the lifetime of the slow decay fraction decreased but the lifetime of the fast decay fraction increased with increasing excitation intensity, indicating that the PL decay is due to the bimolecular recombination. As discussed previously, we analyze this PL decay dynamics on the basis of the bimolecular recombination and the trapassisted SRH recombination in $\mathrm{CH}_{3} \mathrm{NH}_{3} \mathrm{PbI}_{3}$ perovskites. The slow fraction is ascribed to the radiative recombination lifetime $\left(\tau_{\text {rad }}\right)$ and the fast fraction is to the trap-assisted SRH 
recombination lifetime $\left(\tau_{\mathrm{SRH}}\right)$. The radiative recombination lifetime is inversely proportional to the density of free charge carriers, which is given by Equation (1)

$$
\tau_{\mathrm{rad}}=\frac{1}{B_{\mathrm{rad}}\left(\Delta n+n_{0}+p_{0}\right)}
$$

where $B_{\mathrm{rad}}$ is the radiative recombination coefficient, $\Delta n$ is the density of electrons photogenerated under the illumination, and $n_{0}$ and $p_{0}$ are the density of electrons and that of holes generated by unintentional doping, which are given by Equations (2) and (3), respectively.

$$
\begin{aligned}
& n_{0}=N_{\mathrm{C}} \exp \left(\frac{E_{\mathrm{f}}-E_{\mathrm{C}}}{k_{\mathrm{B}} T}\right) \\
& p_{0}=N_{\mathrm{V}} \exp \left(\frac{E_{\mathrm{V}}-E_{\mathrm{f}}}{k_{\mathrm{B}} T}\right)
\end{aligned}
$$

Here, $N_{\mathrm{C}}$ and $N_{\mathrm{V}}$ are the effective density of states in conduction and valence bands, which are given by $N_{\mathrm{C}}=2\left(2 \pi m^{*}{ }_{\mathrm{n}} k_{\mathrm{B}} T / h^{2}\right)^{3 / 2}$ and $N_{\mathrm{V}}=2\left(2 \pi m^{*}{ }_{\mathrm{p}} k_{\mathrm{B}} T / h^{2}\right)^{3 / 2}$ where $m^{*}{ }_{\mathrm{n}}$ and $m_{\mathrm{p}}{ }_{\mathrm{p}}$ are the effective mass for electrons and holes, respectively, $k_{\mathrm{B}}$ is the Boltzmann constant, $T$ is the absolute temperature, and $h$ is the Planck constant. On the other hand, the SRH recombination lifetime is given by Equation (4)

$$
\tau_{\mathrm{SRH}}=\frac{\tau_{\mathrm{p}}\left(n+n_{1}\right)+\tau_{\mathrm{n}}\left(p+p_{1}\right)}{n_{0}+p_{0}+\Delta n}
$$

where $n$ and $p$ are given by $n=\Delta n+n_{0}$ and $p=\Delta p+p_{0}$ where $\Delta p$ is the density of holes photogenerated under the illumination, $n_{1}$ and $p_{1}$ are the density of electrons and that of holes when the Fermi levels of electron and hole coincide with the trap level, which are expressed by Equation (5) and (6), respectively.

$$
\begin{aligned}
& n_{1}=N_{\mathrm{C}} \exp \left(\frac{E_{\mathrm{t}}-E_{\mathrm{C}}}{k_{\mathrm{B}} T}\right) \\
& p_{1}=N_{\mathrm{V}} \exp \left(\frac{E_{\mathrm{V}}-E_{\mathrm{t}}}{k_{\mathrm{B}} T}\right)
\end{aligned}
$$

Here, $\tau_{\mathrm{n}}$ and $\tau_{\mathrm{p}}$ are the lifetime of electrons and holes related to the trapped sites, which are given by Equation (7) and (8), respectively,

$$
\tau_{\mathrm{n}}=\frac{1}{\sigma_{\mathrm{n}} v_{\mathrm{th}}^{\mathrm{n}} N_{\mathrm{t}}}
$$




$$
\tau_{\mathrm{p}}=\frac{1}{\sigma_{\mathrm{p}} v_{\mathrm{th}}^{\mathrm{p}} N_{\mathrm{t}}}
$$

where $\sigma_{\mathrm{n}}$ and $\sigma_{\mathrm{p}}$ are the capture cross sections with trap for electrons and holes, respectively, $N_{\mathrm{t}}$ is the density of trap states with an energy $E_{\mathrm{t}}$ in the bandgap, and $V^{\mathrm{n}}$ th and $V^{\mathrm{p}}$ th are the thermal velocity for electrons and holes, which are defined as $V^{\mathrm{n}}{ }_{\mathrm{th}}=\left(3 k_{\mathrm{B}} T / m^{*}{ }_{\mathrm{n}}\right)^{1 / 2}$ and $V^{\mathrm{p}} \mathrm{th}_{\mathrm{h}}=$ $\left(3 k_{\mathrm{B}} T / m_{\mathrm{p}}^{*}\right)^{1 / 2}$, respectively. We estimated $B_{\mathrm{rad}}$ and $N_{\mathrm{t}}$ on the basis of Equation (1) and (4) by using the parameters taken from the literature, respectively: $\sigma_{\mathrm{n}}=10^{-15} \mathrm{~cm}^{2}$ and $m^{*}{ }_{\mathrm{n}}=0.23 m_{0}$ where $m_{0}$ is the mass of stationary electron. ${ }^{27,28)}$ We assumed that the energy difference between the conduction band and the Fermi level is $E_{\mathrm{C}}-E_{\mathrm{f}}=0.30 \mathrm{eV}$ because $\mathrm{CH}_{3} \mathrm{NH}_{3} \mathrm{PbI}_{3}$ perovskites are considered to be n-type materials caused by an unintentional doping as reported previously. ${ }^{13,29)}$ As a result, as shown in Figure 5a, the intensity dependence of the slow fraction was well fitted by this model with a parameter of $B_{\text {rad }}=8.0 \times 10^{-9} \mathrm{~cm}^{3} \mathrm{~s}^{-1}$ regardless of the grain sizes, which is comparable to that of the previous report. ${ }^{13,30)}$ On the other hand, as shown in Figure 5b, the intensity dependence of the fast fraction was well fitted with $E_{\mathrm{C}}-E_{\mathrm{f}}=0.30 \mathrm{eV}$ and $E_{\mathrm{C}}-E_{\mathrm{t}}=0.38 \mathrm{eV}$. As summarized in Table 1, $N_{\mathrm{t}}$ was evaluated to be $4.58 \times 10^{16} \mathrm{~cm}^{-3}$ for $\approx 100 \mathrm{~nm}, 2.33 \times 10^{16} \mathrm{~cm}^{-3}$ for $\approx 300 \mathrm{~nm}$, and $8.77 \times$ $10^{15} \mathrm{~cm}^{-3}$ for $\approx 500 \mathrm{~nm}$ grain size of $\mathrm{CH}_{3} \mathrm{NH}_{3} \mathrm{PbI}_{3}$ perovskites, which are in good agreement with that obtained from the intensity-dependent $V_{\mathrm{OC}}$ analysis as reported previously. ${ }^{13)}$ This agreement would ensure the reliability of these parameters estimated in this study.

\subsection{Primary Loss Mechanism}

Finally, we discuss the primary loss mechanism of photoexcited states in $\mathrm{CH}_{3} \mathrm{NH}_{3} \mathrm{PbI}_{3}$ perovskites. As shown in Table $1, B_{\mathrm{rad}}$ was independent of the grain size of perovskites while $N_{\mathrm{t}}$ increased from $8.77 \times 10^{15}$ to $4.58 \times 10^{16} \mathrm{~cm}^{-3}$ with decreasing grain size of perovskites from $\approx 500$ to $\approx 100 \mathrm{~nm}$. This indicates that the primary loss mechanism in the excited state of $\mathrm{CH}_{3} \mathrm{NH}_{3} \mathrm{PbI}_{3}$ perovskites is the trap-assisted SRH recombination, which is a nonradiative loss rather than the bimolecular radiative recombination. This result is consistent with our previous report of the primary charge recombination mechanism for $\mathrm{CH}_{3} \mathrm{NH}_{3} \mathrm{PbI}_{3}$ perovskites solar cells analyzed by intensity dependence of $V_{\mathrm{OC}}$. We further discuss how such charge traps have impact on the charge collection under the short-circuit condition in $\mathrm{CH}_{3} \mathrm{NH}_{3} \mathrm{PbI}_{3}$ perovskite solar cells. The charge collection time is given by $\tau_{\mathrm{CC}}$ 
$=L^{2} / 2 \mu V_{\mathrm{OC}}$ where $L$ is the thickness of the active layer and $\mu$ is the charge carrier mobility. Recent studies have shown that $\mu$ in $\mathrm{CH}_{3} \mathrm{NH}_{3} \mathrm{PbI}_{3}$ perovskites is as high as $1-100 \mathrm{~cm}^{2} \mathrm{~V}^{-1}$ $\mathrm{s}^{-1}$.3,5) Here, we thus assumed that $\mu$ is $1 \mathrm{~cm}^{2} \mathrm{~V}^{-1} \mathrm{~s}^{-1}$ as a lower limit. As shown in Table 2, $\tau_{\mathrm{CC}}$ was as short as $\leq 10^{-9} \mathrm{~s}$, which is consistent with the charge injection time reported previously by considering the difference in the thickness. ${ }^{31)}$ This collection time was much shorter than the shorter PL lifetime $\tau_{\text {fast }}$ even under the lowest excitation intensity of $0.6 \mathrm{~nJ}$ $\mathrm{cm}^{-2}$, indicating that the charge collection efficiency is as high as $\sim 100 \%$. In other words, the shorter PL lifetime would have negligible impact on the photocurrent generation or collection in $\mathrm{CH}_{3} \mathrm{NH}_{3} \mathrm{PbI}_{3}$ perovskite solar cells. In summary, these findings indicate that charge traps in perovskites cause the $V_{\mathrm{OC}}$ loss but have no impact on the $J_{\mathrm{SC}}$ in the devices.

\section{Conclusions}

We fabricated flat and dense $\mathrm{CH}_{3} \mathrm{NH}_{3} \mathrm{PbI}_{3}$ perovskites with different grain sizes ranging from $\approx 100$ to $\approx 500 \mathrm{~nm}$ by the FDC method using different concentration of $\mathrm{CH}_{3} \mathrm{NH}_{3} \mathrm{PbI}_{3}$ stock solution. The photoexcited dynamics were studied for the corresponding samples by the TRPL measurements. As a result, we found that the PL decay can be well analyzed for all the samples by a double-exponential decay function. The two lifetimes were dependent on the excitation intensity, suggesting that bimolecular processes are involved. We also found that the TRPL spectra remain the same over the time range measured. We thus analyzed the PL decay dynamics on the basis of the bimolecular radiative recombination and the trap-assisted SRH recombination. As a result, we found that the $B_{\mathrm{rad}}$ is independent of the grain size of $\mathrm{CH}_{3} \mathrm{NH}_{3} \mathrm{PbI}_{3}$ perovskites while the $N_{\mathrm{t}}$ increases with decreasing their grain size. This suggests that the photoexcited species in $\mathrm{CH}_{3} \mathrm{NH}_{3} \mathrm{PbI}_{3}$ perovskites are primarily deactivated by the trap-assisted SRH recombination, which results in the $V_{\mathrm{OC}}$ loss as reported previously. ${ }^{13)}$ On the other hand, the charge traps have negligible impact on the charge collection or $J_{\mathrm{SC}}$ in the devices. We therefore conclude that of particular importance is to fabricate pure perovskites with low $N_{\mathrm{t}}$ for further enhancement in the photovoltaic performance of $\mathrm{CH}_{3} \mathrm{NH}_{3} \mathrm{PbI}_{3}$ perovskite solar cells.

\section{Acknowledgment}

This work was supported by the JST Advanced Low Carbon Technology Research and 
Template for JJAP Regular Papers (Feb. 2017)

Development (ALCA) program (Solar Cell and Solar Energy Systems). 


\section{References}

1) S. D. Wolf, J. Holovsky, S.-J. Moon, P. Löper, B. Niesen, M. Ledinsky, F.-J. Haug, J.-H. Yum, and C. Ballif, J. Phys. Chem. Lett. 5, 1035 (2014).

2) C. Wehrenfennig, M. Liu, H. J. Snaith, M. B. Johnston, and L. M. Herz, J. Phys. Chem. Lett. 5, 1300 (2014).

3) J. Ma and L.-W. Wang, Nano Lett. 17, 3646 (2017).

4) Q. Lin, A. Armin, R. C. R. Nagiri, P. L. Burn, and P. Meredith, Nat. Photonics 9, 106 (2015).

5) M. Ahmadi, T. Wu, and B. Hu, Adv. Mater. 29, 1605242 (2017).

6) M. E. Ziffer, J. C. Mohammed, and D. S. Ginger, ACS Photonics 3, 1060 (2016).

7) L. Q. Phuong, Y. Nakaike, A. Wakamiya, and Y. Kanemitsu, J. Phys. Chem. Lett. 7, 4905 (2016).

8) N.-G. Park, M. Grätzel, T. Miyasaka, K. Zhu, and K. Emery, Nat. Energy 1, 16152 (2016).

9) W. S. Yang, B.-W. Park, E. H. Jung, N. J. Jeon, Y. C. Kim, D. U. Lee, S. S. Shin, J. Seo, E. K. Kim, J. H. Noh, and S. I. Seok, Science 356, 1376 (2017).

10) M. Imaizumi, T. Ito, M. Yamaguchi, and K. Kaneko, J. Appl. Phys. 81, 7635 (1997).

11) B. Zebentout, Z. Benamara, and T. Mohammed-Brahim, Thin Solid Films 516, 84 (2007).

12) M. K. Sharma and D. P. Joshi, Indian J. Pure Appl. Phys. 48, 575 (2010).

13) H. D. Kim, H. Ohkita, H. Benten, and S. Ito, Adv. Mater. 28, 917 (2016).

14) M. Xiao, F. Huang, W. Huang, Y. Dkhissi, Y. Zhu, J. Etheridge, A. Gray-Weale, U. Bach, Y.-B. Cheng, and L. Spiccia, Angew. Chem. 126, 10056 (2014).

15) M. Maiberg and R. Scheer, J. Appl. Phys. 116, 123710 (2014).

16) M. Maiberg, T. Hölscher, S. Zahedi-Azad, and R. Scheer, J. Appl. Phys. 118, 105701 (2015).

17) A. Redinger, S. Levcenko, C. J. Hages, D. Greiner, C. A. Kaufmann, and T. Unold, Appl. Phys. Lett. 110, 122104 (2017).

18) C. R. Haughn, K. J. Schmieder, J. M. O. Zide, A. Barnett, C. Ebert, R. Opila, and M. F. Doty, Appl. Phys. Lett. 102, 182108 (2013).

19) S. D. Stranks, V. M. Burlakov, T. Leijtens, J. M. Ball, A. Goriely, and H. J. Snaith, Phys. Rev. Appl. 2, 034007 (2014).

20) W. L. Leong, Z.-E. Ooi, D. Sabba, C. Yi, S. M. Zakeeruddin, M. Graetzel, J. M. Gordon, E. A. Katz, and N. Mathews, Adv. Mater. 28, 2439 (2016).

21) T. K. Todorov, O. Gunawan, T. Gokmen, and D. B. Mitzi, Prog. Photovoltaics: Res. Appl. 
21, 82 (2013).

22) H. D. Kim, Y. Miyamoto, H. Kubota, T. Yamanari, and H. Ohkita, Chem. Lett. 46, 253 (2017).

23) H. D. Kim, N. Yanagawa, A. Shimazaki, M. Endo, A. Wakamiya, H. Ohkita, H. Benten, and S. Ito, ACS Appl. Mater. Interfaces 9, 19988 (2017).

24) A. R. bin M. Yusoff and M. K. Nazeeruddin, J. Phys. Chem. Lett. 7, 851 (2016).

25) H. D. Kim and H. Ohkita, Solar RRL 1, 1700027 (2017).

26) Y. Yamada, T. Nakamura, M. Endo, A. Wakamiya, and Y. Kanemitsu, Appl. Phys. Express 7, 032302 (2014).

27) M. L. Agiorgousis, Y.-Y. Sun, H. Zeng, and S. Zhang, J. Am. Chem. Soc. 136, 14570 (2014).

28) W.-J. Yin, J.-H. Yang, J. Kang, Y. Yan, and S.-H. Wei, J. Mater. Chem. A 3, 8926 (2015).

29) Q. Wang, Y. Shao, H. Xie, L. Lyu, X. Liu, Y. Gao, and J. Huang, Appl. Phys. Lett. 105, 163508 (2014).

30) A. R.S. Kandada and A. Petrozza, APL Mater. 4, 091506 (2016).

31) S. Makuta, M. Liu, M. Endo, H. Nishimura, A. Wakamiya, and Y. Tachibana, Chem. Commun. 52, 673 (2016). 


\section{Figure Captions}

Fig. 1. (Black and white) SEM images of $\mathrm{CH}_{3} \mathrm{NH}_{3} \mathrm{PbI}_{3}$ films fabricated by the FDC method using different concentrations of stock solution: a) $25 \mathrm{wt} \%$, b) $45 \mathrm{wt} \%$, and c) $55 \mathrm{wt} \%$. The inset in each figure is AFM images of the same film. The scale bars correspond to $250 \mathrm{~nm}$ in length.

Fig. 2. (Black and white) a) Absorption (solid line) and PL (broken line) spectra of $\mathrm{CH}_{3} \mathrm{NH}_{3} \mathrm{PbI}_{3}$ perovskite films with a grain size of $\approx 500 \mathrm{~nm}$. b) $(E \times \mathrm{EQE})^{2}$ plotted against a photon energy $E$ for $\mathrm{CH}_{3} \mathrm{NH}_{3} \mathrm{PbI}_{3}$ solar cells with different grain sizes: $\approx 100 \mathrm{~nm}$ (open circles), $\approx 300 \mathrm{~nm}$ (open triangles), and $\approx 500 \mathrm{~nm}$ (open squares). The broken lines show the $x$-intercept.

Fig. 3. (Black and white) Intensity dependence of TRPL dynamics for $\mathrm{CH}_{3} \mathrm{NH}_{3} \mathrm{PbI}_{3}$ perovskite films with different grain sizes: a) $\approx 100 \mathrm{~nm}$, b) $\approx 300 \mathrm{~nm}$, and c) $\approx 500 \mathrm{~nm}$. The samples were excited at $1.84 \mathrm{eV}$ and the PL dynamics were monitored at $1.60 \mathrm{eV}$ under different excitation intensities: $2.8 \mathrm{~nJ} \mathrm{~cm}^{-2}$ (close diamonds), $2.1 \mathrm{~nJ} \mathrm{~cm} \mathrm{~cm}^{-2}$ (close inverted triangles), $1.4 \mathrm{~nJ} \mathrm{~cm}^{-2}$ (close squares), $0.9 \mathrm{~nJ} \mathrm{~cm}^{-2}$ (close triangles), and $0.6 \mathrm{~nJ} \mathrm{~cm}^{-2}$ (close circles). The white broken lines represent the fits to the experimental data with a doubleexponential decay function.

Fig. 4. (Black and white) TRPL spectra for $\mathrm{CH}_{3} \mathrm{NH}_{3} \mathrm{PbI}_{3}$ perovskite films with different grain sizes: a) $\approx 100 \mathrm{~nm}$, b) $\approx 300 \mathrm{~nm}$, and c) $\approx 500 \mathrm{~nm}$. The samples were excited at $1.84 \mathrm{eV}$ and the PL dynamics were monitored at $1.60 \mathrm{eV}$ under different delay times: $0 \mathrm{~ns}$ (close circles), $1 \mathrm{~ns}$ (close triangles), $10 \mathrm{~ns}$ (close squares), $50 \mathrm{~ns}$ (close inverted triangles), $100 \mathrm{~ns}$ (close diamonds), and $700 \mathrm{~ns}$ (open circles). The inset in each figure shows the normalized TRPL spectra at the different delay times. 
Fig. 5. (Black and white) a) The longer lifetime, b) the shorter lifetime, and c) the average lifetime as a function of an excess carrier density for $\mathrm{CH}_{3} \mathrm{NH}_{3} \mathrm{PbI}_{3}$ perovskite films with different grain sizes: $\approx 100 \mathrm{~nm}$ (open circles), $\approx 300 \mathrm{~nm}$ (open triangles), and $\approx 500 \mathrm{~nm}$ (open squares). The broken lines and the dashed-dotted lines were extracted by a fit to experimental data with Equation (1) and Equation (4), respectively. The open plots and error bars in the $y$-axis represent the average and the standard deviation of several values measured. 
Table I. Recombination kinetic parameters for $\mathrm{CH}_{3} \mathrm{NH}_{3} \mathrm{PbI}_{3}$ perovskites.

\begin{tabular}{ccccc}
\hline Grain size & \multicolumn{2}{c}{$B_{\mathrm{rad}} / \mathrm{cm}^{3} \mathrm{~s}^{-1}$} & \multicolumn{2}{c}{$N_{\mathrm{t}} / \mathrm{cm}^{-3}$} \\
\cline { 2 - 5 }$/ \mathrm{nm}$ & Device $^{\mathrm{a})}$ & TRPL & Device $^{\mathrm{a})}$ & TRPL \\
\hline$\approx 100$ & $3.0 \times 10^{-9}$ & $8.0 \times 10^{-9}$ & $5.30 \times 10^{16}$ & $4.58 \times 10^{16}$ \\
$\approx 300$ & $3.0 \times 10^{-9}$ & $8.0 \times 10^{-9}$ & $1.05 \times 10^{16}$ & $2.55 \times 10^{16}$ \\
$\approx 500$ & $3.0 \times 10^{-9}$ & $8.0 \times 10^{-9}$ & $2.84 \times 10^{15}$ & $8.77 \times 10^{15}$ \\
\hline
\end{tabular}

${ }^{\text {a) }} B_{\text {rad }}$ and $N_{\mathrm{t}}$ are taken from our previous literature. ${ }^{13)}$

Table II. Comparison between $\tau_{\text {fast }}$, and $\tau_{\mathrm{CC}}$ in $\mathrm{CH}_{3} \mathrm{NH}_{3} \mathrm{PbI}_{3}$ perovskites.

\begin{tabular}{cccc}
\hline Grain size $(L) / \mathrm{nm}$ & $V_{\mathrm{OC}} / \mathrm{V}^{\mathrm{a})}$ & $\tau_{\mathrm{CC}} / \mathrm{ns}$ & $\tau_{\text {fast }} / \mathrm{ns}^{\mathrm{b})}$ \\
\hline$\approx 100$ & 1.00 & $5.0 \times 10^{-11}$ & $1.6 \times 10^{-9}$ \\
$\approx 300$ & 1.04 & $4.3 \times 10^{-10}$ & $2.4 \times 10^{-9}$ \\
$\approx 500$ & 1.08 & $1.2 \times 10^{-9}$ & $7.1 \times 10^{-9}$ \\
\hline
\end{tabular}

a) $V_{\mathrm{OC}}$ are taken from our previous literature. ${ }^{13)}$

b) The values represent the shorter lifetime under an excitation intensity of $0.6 \mathrm{~nJ}$ $\mathrm{cm}^{-2}$. 

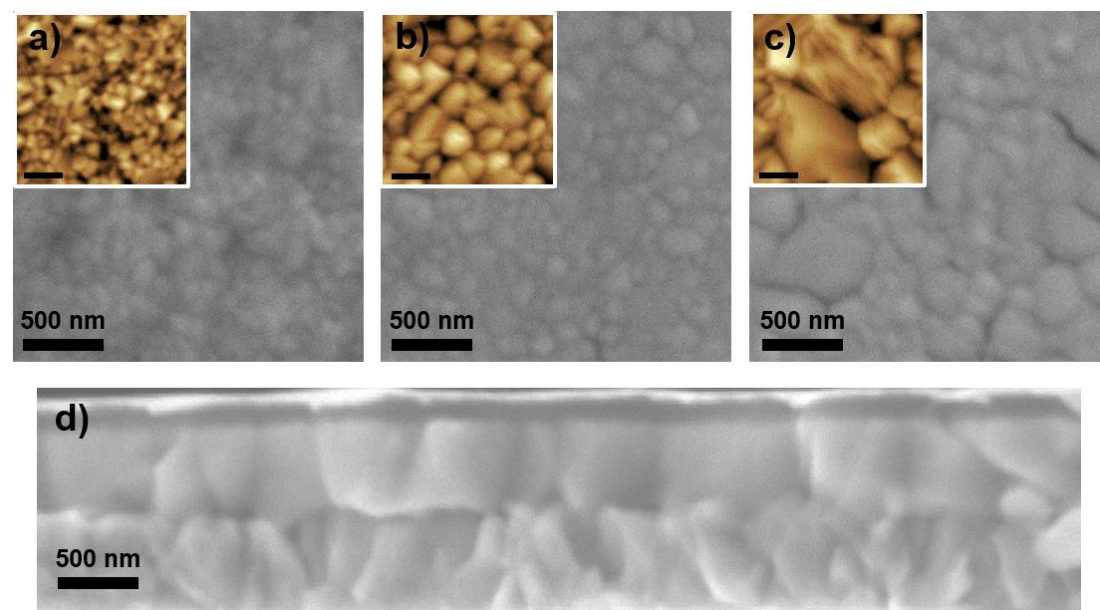

Fig.1. (Black and white) 


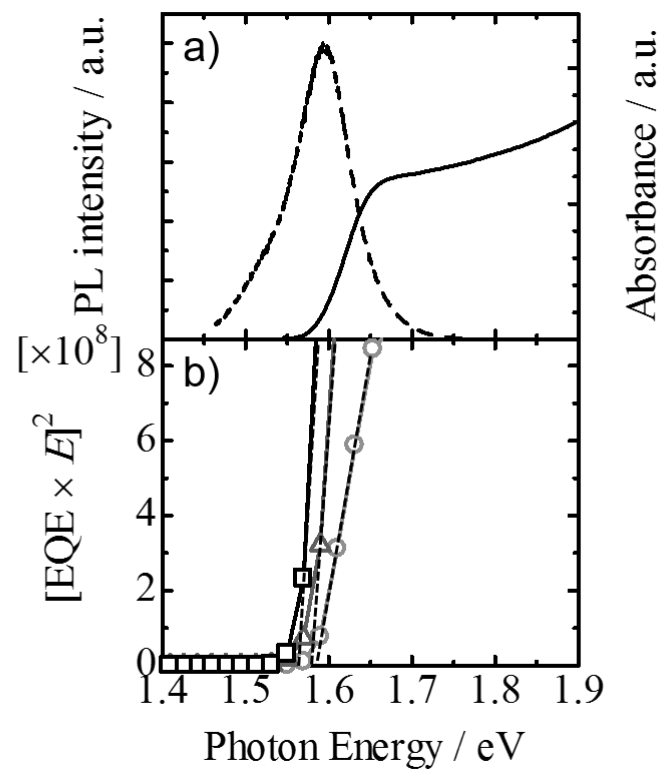

Fig. 2. (Black and white) 


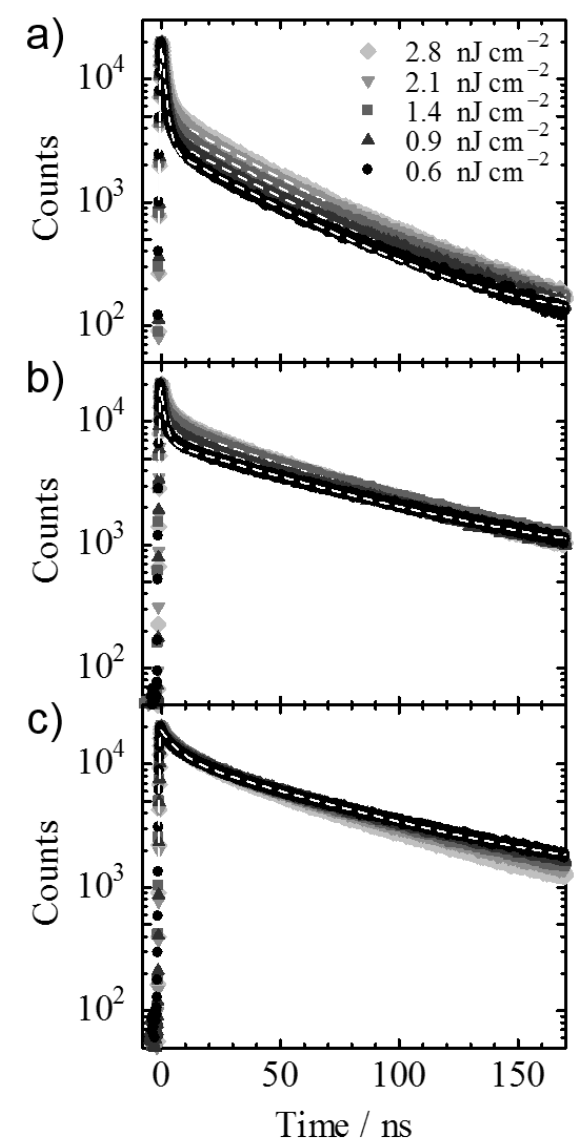

Fig. 3. (Black and white) 


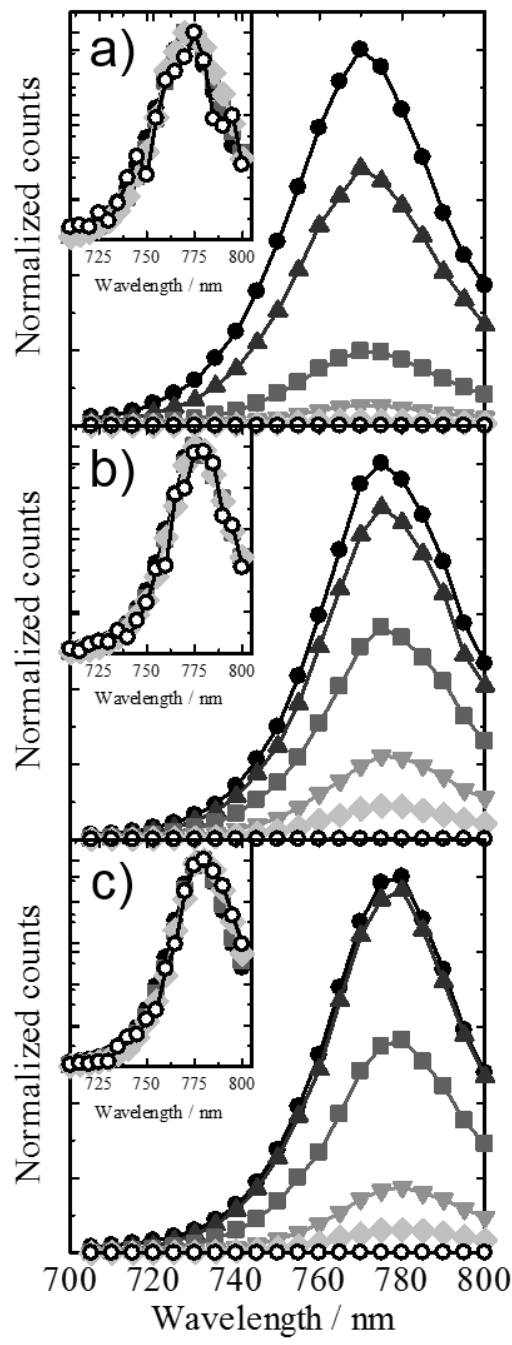

Fig. 4. (Black and white) 


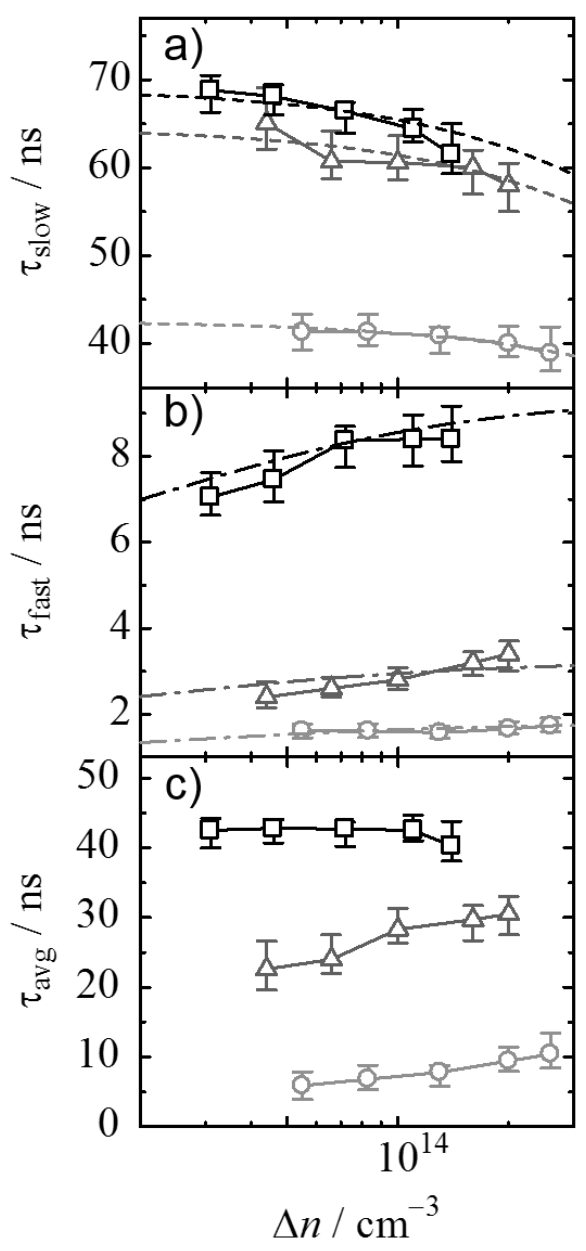

Fig. 5. (Black and white) 